\begin{tabular}{|c|c|}
\hline \multicolumn{2}{|l|}{ Abstract 166 Table 2} \\
\hline & All paticnts $(n-10)$ \\
\hline \multicolumn{2}{|l|}{ NRS at rest } \\
\hline 2 bours & $5(2-6.5)$ \\
\hline 24 hours & $0.5(0-2)$ \\
\hline 48 hours & $1(0-2)$ \\
\hline \multicolumn{2}{|l|}{ NRS con movement } \\
\hline 2 hours & NA \\
\hline 24 hours & $3(3-5.5)$ \\
\hline 48 hours & $3.5(3-5)$ \\
\hline \multicolumn{2}{|l|}{ Total amouns of postoperative fentanyl use in $\mu \mathrm{g} \mathrm{kg}$} \\
\hline $0-12$ hours & $6.1(5.1-6.7)$ \\
\hline $12-24$ bours & $5.7(4.6-8.4)$ \\
\hline $24-36$ hours & $4.6(1.9-6.2)$ \\
\hline $36-48$ bours & $3.0(0.6-3.9)$ \\
\hline Postopcrative nausea and vomit within 48 bours $(+i-)$ & 46 \\
\hline \multicolumn{2}{|l|}{ Number of additional andgesics use, n (\%) } \\
\hline 0 tims & $8(90 \%)$ \\
\hline 3 timss & $2(20 \% 6)$ \\
\hline Paticnt satisfaction & $8.5(8-10)$ \\
\hline
\end{tabular}

dermatomes at 2 and $24 \mathrm{~h}$ postoperatively were 6 (5-7) and $6.5(5-7)$ in the anterior cutaneous branch area, and 5 (4-7) and 7 (5-7) in the lateral cutaneous branch area, respectively. (Figure 1) There was an $85 \%$ chance of simultaneously acquiring the Th8-Th11 analgesic area including completely blocking Th9-10 in the anterior cutaneous branch area. Results are presented in table 2. Cadaveric evaluation showed the spread of the dye in Th8-11.

Conclusions M-TAPA may provide an analgesic effect in Th811 in the anterior cutaneous branch area.

\section{ULTRASOUND GUIDED COSTOCLAVICULAR BRACHIAL PLEXUS BLOCK FOR PROXIMAL HUMERUS FRACTURE WITH PNEUMOTHORAX IN AN ELDERLY PATIENT - A CASE REPORT}

A Baskaran*, G P, S D, B J. Ganga Medical Centre and Hospitals pvt Itd, Coimbatore, India

\subsection{6/rapm-2021-ESRA.167}

Background and Aims Patients with proximal humeral fractures present a unique challenge to anesthesiologists because no single brachial plexus block adequately covers the entire distribution of the upper extremity. It is more complicated in the presence of multiple trauma with rib fractures and pneumothorax.
Methods We report a case of 70 year old male,ASA II admitted with polytrauma. Radiological investigations revealed closed fracture of right humerus and right distal radius with left sided mild pneumothorax following multiple left sided rib fractures and was scheduled for right humerus plating along with bone grafting and closed reduction of right distal radius. Inside operation theatre, standard monitors were attached and oxygen support was provided. Under sterile aseptic precautions, patient in supine position, a linear array Ultrasound probe $(5-13 \mathrm{MHz}$, Sonosite, USA) was used. Under Ultrasound

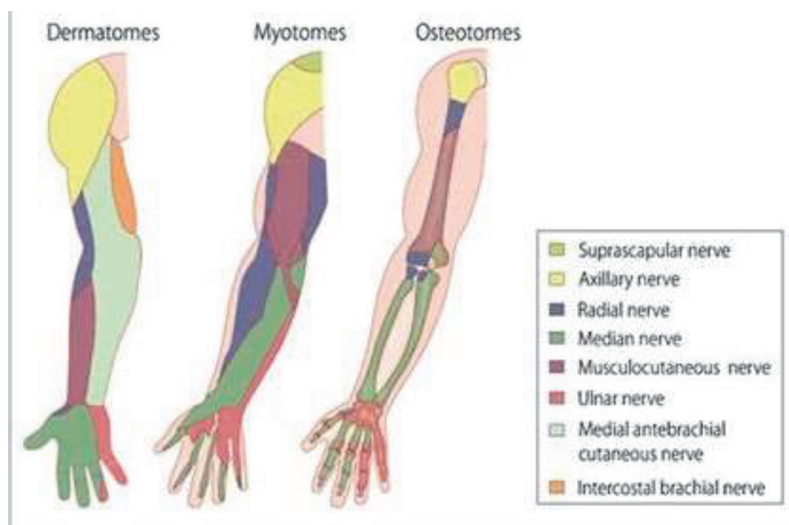

Abstract 167 Figure 1

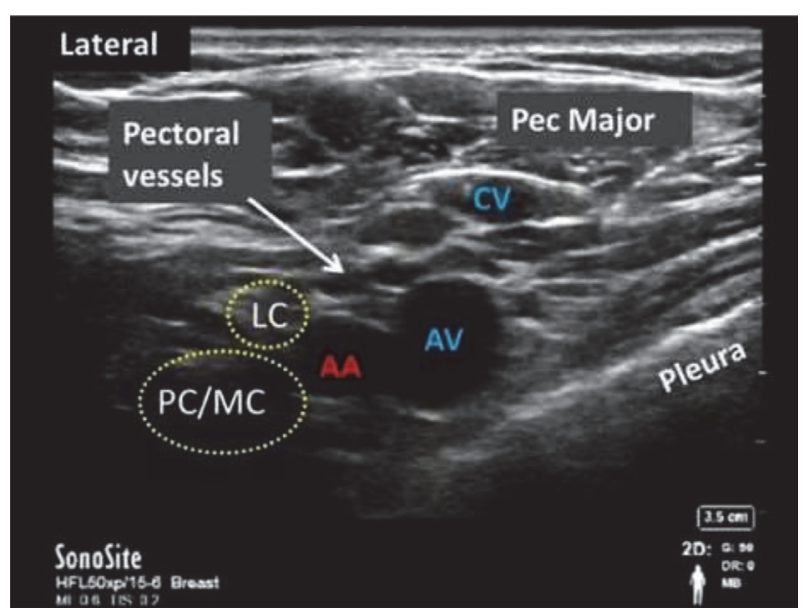

Abstract 167 Figure 3
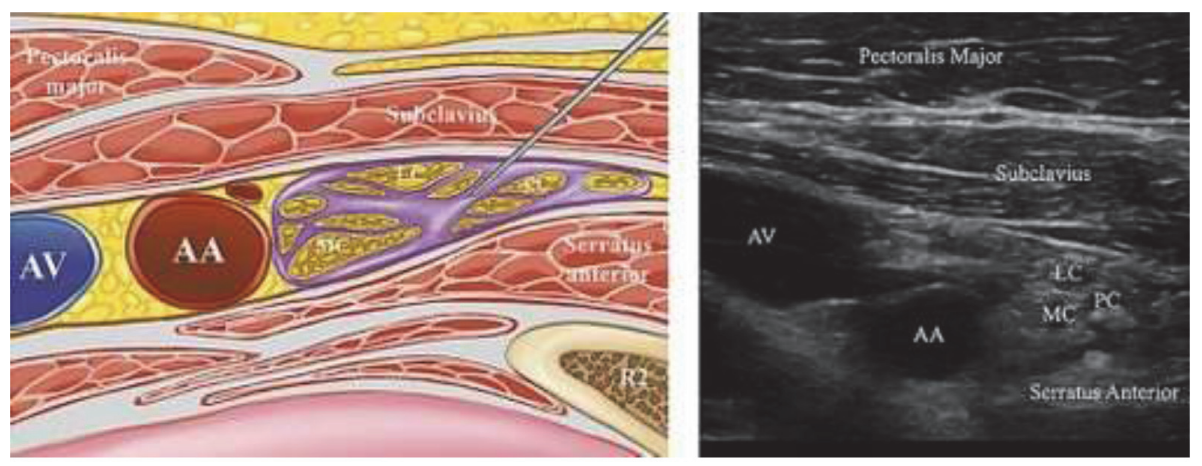
guidance, 21G,1.5inch needle was inserted in-plane approach. Right Costoclavicular block was given with $15 \mathrm{ml}$ of $0.75 \%$ Ropivacaine with $8 \mathrm{mg}$ Inj. Dexamethasone and subcutaneous infiltration of $10 \mathrm{ml}$ of $2 \%$ lignocaine with adrenaline for the blockade of intercostobrachial nerve and posterior cutaneous nerve of arm.

Results Costoclavicular block is also effective in the blockade of upper trunk of brachial plexus due to chimney effect. In the infraclavicular region, the neurovascular plexus sheath forms longitudinal septae between the cords that limits the circumferential spread of local anesthetics resulting in sparing of phrenic nerve. The success of anesthetic block is higher with multiple injections compared to single injection technique.

Conclusions Costoclavicular block is safer alternative for upper limb surgeries in case of polytrauma with compromised lung function.

\section{PLAN A BLOCKS COURSE}

T Al-Ani*, R Murphy. Glasgow Royal Infirmary, Glasgow, UK

\subsection{6/rapm-2021-ESRA. 168}

Background and Aims The consistency in education and training of regional anaesthesia could be achieved by focusing teaching on basic level yet high value nerve blocks. This quality improvement project aims to standardise regional anaesthesia teaching for anaesthetic trainees by delivering a 'Plan A' blocks course which covers: Interscalene brachial plexus (BP),

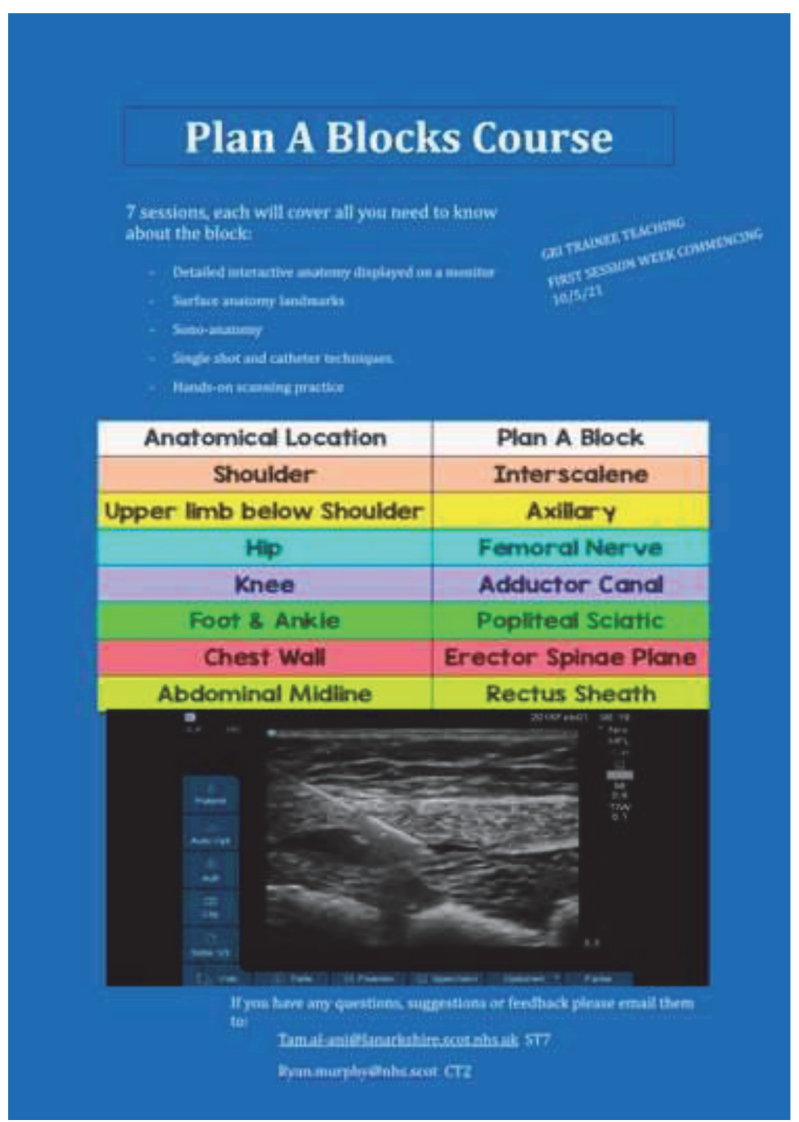

Abstract 168 Figure 1
Axillary BP, Femoral nerve, Adductor canal, Popliteal sciatic, Erector spine and Rectus sheath.

Methods The course is delivered across seven sessions and repeated four times a year. Each session is focused on one block at a time and lasts for one hour, covering: detailed anatomy, sono-anatomy, landmarks and ultrasound guided block techniques. Then, trainees get supervised hands on practice of landmarks and ultrasound scanning of a model. Ethics approval is not required as per NHS Greater Glasgow and Clyde policy.

Results The course is added to our formal anaesthetic department teaching. All attendees feedback has been positive, with all stating they would be more confident performing the 'Plan A' blocks after this course. This strongly supports the focused learning of one block at a time.

Conclusions Designing and delivering a 'Plan A' blocks course focusing on one core nerve block per session could improve the quality of regional anaesthesia learning.

\section{THE INFLUENCE OF COVID-19 PANDEMIC ON THE USE OF ULTRASOUND-GUIDED REGIONAL ANESTHESIA/ ANALGESIA TECHNIQUES FOR ORTHOPEDIC SURGERY CASES IN LESKOVAC GENERAL HOSPITAL, SERBIA}

${ }^{1} \mathrm{~N}$ Pejčić*, ${ }^{1} \mathrm{R}$ Mitić, ${ }^{1} \mathrm{M}$ Jović, ${ }^{2}$ Velickovic, ${ }^{3} \mathrm{~N}$ Sadana. 'Leskovac General Hospital, Leskovac, Serbia; ${ }^{2}$ SUNY Downstate, Brooklyn, USA; ${ }^{3}$ Tufts, Boston, USA

\subsection{6/rapm-2021-ESRA.169}

Background and Aims In Serbia, the use of regional anesthesia and analgesia (RA) techniques in orthopedic surgery cases has been low, despite sporadic efforts to increase the use. Thanks to the Kybele international teaching visit held in April 2017, members of the Department of Anesthesia at Leskovac General Hospital, Serbia (LGH) started doing ultrasound-guided RA (UGRA) techniques.

Methods From the LGH anesthesia database for period January 2016 to December 2020 data on all upper and lower extremity (LE) surgeries were obtained.

Results During the study period, there was an increase in neuraxial anesthesia (NA) use for LE surgery (2016 - 60\%, 2020

Abstract 169 Table 1

\begin{tabular}{|c|c|c|c|c|c|}
\hline \multicolumn{2}{|c|}{ Type of Surgery \Year } & 2017 & 2018 & 2019 & 2020 \\
\hline \multirow{4}{*}{ THA } & FIB & 1 & 1 & 0 & 0 \\
\cline { 2 - 6 } & QLB & 0 & 2 & 4 & 1 \\
\cline { 2 - 6 } & ESPB & 0 & 0 & 7 & 2 \\
\hline \multirow{4}{*}{ TKA } & ACB & 10 & 8 & 5 & 0 \\
\cline { 2 - 6 } & ACB + IPACK & 0 & 0 & 8 & 3 \\
\hline \multirow{4}{*}{ Lower Leg Surgery } & FNB & 2 & 0 & 0 & 0 \\
\cline { 2 - 6 } & SNB + FNB & 0 & 1 & 0 & 1 \\
\hline \multirow{5}{*}{ Arm Surgery } & Poppl.NB & 0 & 1 & 2 & 1 \\
\cline { 2 - 6 } & Poppl.NB+ACB & 7 & 8 & 5 & 4 \\
\hline & Interscalene NB & 1 & 1 & 0 & 1 \\
\cline { 2 - 6 } & Supraclavicular NB & 5 & 8 & 5 & 4 \\
\cline { 2 - 6 } & Axillar NB & 0 & 2 & 0 & 0 \\
\cline { 2 - 6 } & ESPB & 0 & 0 & 3 & 1 \\
\hline
\end{tabular}

